\title{
Special issue: III Congress of Theoretical and Computational Physical Chemistry, 2-4 of December of 2010, Altos de Pipe, Caracas, Venezuela
}

\author{
Humberto Soscun ${ }^{\mathrm{a}, \mathrm{b}}$, Fernando Ruette ${ }^{\mathrm{c}}$ and Anibal Sierralta ${ }^{\mathrm{c}}$ \\ ${ }^{a}$ Centro Tecnológico, Instituto Venezolano de Investigaciones Científicas, IVIC Caracas, Venezuela \\ ${ }^{\mathrm{b}}$ Departamento de Química, Facultad Experimental de Ciencias, La Universidad del Zulia \\ LUZ,Maracaibo, Venezuela \\ ${ }^{\mathrm{c}}$ Centro de Química, Instituto Venezolano de Investigaciones Científicas IVIC, Caracas, Venezuela
}

This special issue of the Journal of Computational Methods in Science and Engineering (JCMSE) consists of a selection of papers about the presentations in the III Congress of Theoretical Physical and Computational Chemistry III-CFQTC, held at Altos de Pipe, Caracas, in the Instituto Venezolano de Investigaciones Científicas IVIC, from 02 to 04 December 2010. The articles were written by the most important Venezuelan scientists in areas of molecular modeling, theoretical chemistry, computational catalysis, bioinformatic and medicinal chemistry, calculations of reaction mechanisms and kinetics, prediction of molecular electric and magnetic properties and chemical process simulation in the industry, as stated in the II CFQTC held at Choroní, 2008.

Invited researchers attended to the III-CFQTC with 8 plenary lectures of high scientific quality and more than 80 posters distributed in two sessions were also presented. The attendance was circa 100 participants from different universities and research institutes. Participants were invited to submit manuscripts of their presentation for a JCMSE special issue, from which 19 of them were accepted after a careful peer review process. We wish to thanks the speakers for their lucid and interesting conferences. Also, we greatly appreciate all the persons and institutions allowing III CFQTC to be held in Venezuela: IVIC, Intevep-PDVSA, Universidad Nacional de Colombia, Academia Venezolana de Ciencias Físicas Matemáticas y Naturales, Universidad Central de Venezuela (UCV), Universidad de Los Andes (LUZ), Universidad Simón Bolívar (USB) and also private enterprises as Fundación Empresas Polar. They kindly contributed to the costs of travelling and lodging of some of the invited speakers. The offer of JCMSE to publish extended evaluated manuscripts has been also a very important support for the success of the III-CFQTC.

Invited Speakers:

Javier Fernández Sanz, Departamento de Físico-Química, Universidad de Sevilla, España. 
Maricarmen Grisolía, Centre d'Elaboration de Matériaux et d'Études Sructurales (CEMES), Toulouse, Francia.

Rincón Luis,(Carlos González), Nacional Institute of Standards Technology, (NIST) USA; Escuela de Química, Facultad de Ciencias, Universidad de Los Andes, Mérida, Venezuela.

Vladimiro Mujica, Arizona State University, Arizona, Phoenix, USA.

José Antonio Rodríguez, Chemistry Department, Brookhaven National Laboratory, Upton, USA.

Andrés Reyes, Universidad Nacional de Colombia, Bogotá, Colombia

Roberto Galiasso, Oklahoma University Department of Chemical Biological \& Materials Engineering, Norman, Oklahoma 73019 USA.

María Luisa Serrano, Unidad de Química Medicinal, Facultad de Farmacia, Universidad Central de Venezuela.

Leonardo Sigalotti. Laboratorio de Física de Fluidos y Plasmas, Centro de Física, IVIC, Caracas, Venezuela.

Claudio Olivera-Fuentes, Grupo TADIP, Departamento de Termodinámica y Fenómenos de Transferencia, Universidad Simón Bolívar, Caracas, Venezuela

Jhoan Toro, Centro de Estudios Interdisciplinarios de la Física. Laboratorio de Dispersiones e Interfases, Centro de Física, IVIC, Caracas, Venezuela. 